\title{
Breeding programs for smallholder farming systems: 1. Evaluation of alternative designs of breeding schemes for Menz sheep
}

\author{
Solomon Gizaw ${ }^{\mathrm{a} *}$, Barbara Rischkowsky ${ }^{\mathrm{b}}$, Anne Valle-Zárate ${ }^{\mathrm{c}}$, Aynalem Haile ${ }^{\mathrm{b}}$, Johan van \\ Arendonk $^{\mathrm{d}}$, Ally Okeyo Mwai ${ }^{\mathrm{e}}$, Tadelle Dessie ${ }^{\mathrm{a}}$ \\ ${ }^{a}$ International Livestock Research Institute, P.O. Box 5689, Addis Ababa, Ethiopia \\ ${ }^{\mathrm{b}}$ University of Hohenheim, Department of Animal Breeding and Husbandry in the Tropics and \\ Subtropics, P.O. Box 70593 Stuttgart, Germany \\ 'International Centre for Agricultural Research in the Dry Areas, ICARDA, P.O. Box 5466 Aleppo, \\ Syria \\ ${ }^{\mathrm{d}}$ Animal Breeding and Genomics Centre, Wageningen University, P.O. Box 338, $6700 \mathrm{AH}$, \\ Wageningen, The Netherlands \\ ${ }^{e}$ International Livestock Research Institute, P.O. Box 30709, Nairobi, Kenya
}

Running title: Designs of breeding schemes for smallholder farming systems

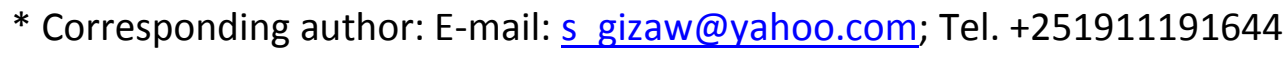




\section{Abstract}

Three village-based and three central nucleus-based sheep breeding schemes were modeled by deterministic simulations and evaluated in terms of their biological and economic efficiencies as well as their feasibility to implement under smallholder sheep farming systems, taking Menz sheep of Ethiopia as a case study. The schemes were - Scheme-1: a two-tier cooperative village breeding scheme, Scheme-2: a one-tier cooperative village breeding scheme, Scheme-3: dispersed village-based nuclei scheme; Schem-4: conventional two-tier central nucleus-based scheme, Schem-4: central nucleus linked to village nuclei, with selection in central nucleus, Scheme-6: central nucleus linked to village nuclei, with selection in both central and village nuclei. Among village-based schemes, Scheme-1 gave faster genetic progress than scheme-2, but Scheme-2 was economically more efficient and seems to be operationally more feasible since setting up and maintaining a nucleus flock within a cooperative breeding village is rather infeasible. Among the central nucleus schemes, Scheme-4 seems to be the most efficient, but operationally difficult as it requires a very large central nucleus flock of about 11241 ewes. Scheme-6 resulted in lower genetic gains and profits, but is operationally more feasible under smallholder system. In general, higher genetic gains and profits could be achieved from central nucleus-based schemes than from village-based schemes. However, when relative distribution of economic returns to the various producer/breeder groups across the breeding structure was considered, village-based schemes were found to be more efficient, $100 \%$ of the profits being retained by the producer farmers. The choice of central nucleus- or village-based schemes depends on local conditions with respect to availability of infrastructures and logistics. Linking central nucleus flocks with village-based nuclei (Scheme-6) is a feasible option to overcome the operational difficulties of the conventional nucleus scheme. Scheme-2 is the most efficient to design genetic improvement within individual villages, whereas its extension (Scheme-3) could be adopted to design breeding programs addressing the whole Menz sheep population.

Key words: Breeding programs; smallholder system; Sheep; 


\section{Introduction}

Developing livestock breeding programs involves identification of breeding-objective traits, derivation of economic values for traits, designing appropriate schemes which define the population structure, gene flow and selection strategy, and preparing the breeding plan. The research effort in designing breeding programs in Ethiopia and other developing countries has so far largely focused on definition of breeding objectives. However, the major bottleneck in designing breeding programs for smallholder systems is defining breeding schemes/structures that are suitable for the low input smallholder farming system. Mueller (2010) defined breeding structures as stratification of animals for mating and stressed that the choice and operation of an adequate stratification can be a challenging task in low input systems.

Designs of breeding schemes that are deemed suitable for smallholder farming systems can be categorized into village-based (also called community-based) and central nucleus based breeding schemes. Government or state-operated central nucleus based breeding programs (Smith, 1988; Kosgey, 2004; Gizaw et al. 2007) are criticized for being unsuitable for low-input production systems (Kosgey et al., 2006) and some have failed (Okeyo, 2002; Ahuya et al., 2005; Kosgey, 2004; Singh et al., 2005). Recently, village-based single-tier breeding programs where genetic improvement is generated within village flocks kept for production have been suggested (Croston and Pollot, 1994; Sölkner, 1998; Wurzinger et al. 2008; Gizaw et al. 2009; Haile et al., 2011; Mirkena et al., 2012).

The failure of central nucleus based breeding programs could be due to technical limitations, absence of infrastructures to support the breeding programs (Kosgey et al., 2006) and managemental problems including lack of long term commitment by research and 
development institutes, technical expertise and participation of farmers in the design and implementation of breeding programs. The technical problems include inappropriate expertderived breeding objectives, mismatch between the environments under which central nucleus breeders operate and village conditions (Kosgey et al., 2007), and the prohibitively large central nucleus flock required to sustain genetic improvement at the breed level (i.e. addressing the whole breed population). A major technical limitation in village-based schemes (e.g. Gizaw et al., 2009; Mirkena et al., 2012) is that they target genetic improvement within individual village flocks and do not show how genetic improvement can be implemented at breed level. It is also rather difficult to implement selection on BLUP breeding values in village flocks due to the difficulty of pedigree recording. Thus, alternative innovative designs that overcome the above mentioned technical obstacles in both central nucleus- and village-based breeding programs need to be explored. The purpose of the present study was to identify existing central nucleus and village-based schemes from the literature, design novel schemes and evaluate them in terms of their biological and economic efficiencies as well as their feasibility to implement under smallholder sheep farming systems, taking Menz sheep of Ethiopia as a case study.

\section{Material and methods}

\section{Description of production system}

Menz sheep are found in the subalpine highlands of Menz region in Ethiopia with an altitude of around $3200 \mathrm{~m}$ above sea level. The breeding tract of Menz sheep extends across five districts in Menz region, namely Menz Gera, Menz Qeya, Menz Gishe, Menz Mama, and Menz Lallo districts. Temperature in the area varies from -4 to $+18{ }^{\circ} \mathrm{C}$ and frost is common between October and November. The area is thus less suitable to cropping and farmers largely 
depend on sheep farming for their livelihoods. Farmers keep small flocks of sheep under lowinput and low-output production system.

The traditional breeding practice varies among farmers depending on farmers' breeding skills and socio-economic needs. The common breeding practice is random selection, with no clear and consistent selection criteria leading to several of breeding rams being used in flocks. Some farmers practice selection of rams for breeding based on the animals' appearance (horn,

tail, color) and conformation (pelvic width, body length). However, selection intensities are low as selection of rams is carried out within the respective small flocks. Some of the farmers also practice negative selection against good performing animals unintentionally by culling and selling the best animals to fetch higher market prices to fulfill immediate cash needs. The mating practices are uncontrolled and year round. All the flocks are grazed in communal grazing lands together. Thus both selected and unselected rams of the whole village are running with the flocks under communal village mating system. Breeding rams are commonly used for 2-3 years.

\section{Breeding goal and selection criteria}

The Menz sheep farmers breeding goal defined in previous studies (Gizaw et al., 2010; Duguma et al., 2011; Mirkena et al., 2012) was adopted for the current simulation study. The breeding-objective traits identified included 6-month weight (SWT), mature weight (MWT), preweaning lamb survival (PWS), litter size (LTS) and appearance (coat color, horn, etc.). Preweaning lamb survival was measured as the trait of the ewe (i.e. the dam's lamb rearing ability). Although the trait mature weight has not been specifically mentioned by Menz farmers, 
it has been included in the current study as it is highly related to lamb growth and ewe lamb rearing ability.

Bio-economic models were constructed on Microsoft Excel spread sheet to derive economic values of traits, considering both tangible (direct regular cash income from sale of surplus lambs, finished lambs, culled animals, manure and skin) and intangible benefits (insurance and financing benefits) of rearing Menz sheep. The intangible benefits were estimated following Bosman et al. (1997). Economic values for each trait were estimated as a change in profit resulting from an increase in one additive genetic standard deviation in the trait value due to selection. The estimated economic values for SWT, MWT, PWS, and LTS are presented in Table 2. The selection criteria used in the current study were SWT and PWS.

\section{Description of alternative designs of breeding schemes}

Six alternative breeding schemes were identified and modeled. The schemes identified were either village-based (Schemes 1-3) or central nucleus-based (Schemes 4-6; Table 1). The schemes address genetic improvement activities either at a village level (Schemes 1 and 2) or at regional level covering the whole Menz sheep population in the five districts of Menz region. A village is defined here as a group of contiguous communities sharing communal grazing areas with little or no interference from other village flocks and which have about 1200-1500 breeding ewes. The population of Menz sheep in the five districts in the Menz sheep breeding tract is estimated at 208169 , of which $54 \%$ are breeding ewes. The six schemes were simulated using the method developed for this purpose and incorporated in the computer program ZPLAN (Willam, et al., 2008). The six schemes are described below. 
1. Scheme-1 (Two-tier cooperative village breeding scheme) - The scheme involves cooperation among farmers in a village where they establish a village-based nucleus flock by contributing their best females to the nucleus. Selection is carried out in the nucleus which will supply improved rams to the cooperative group within the village (Croston and Pollot, 1994; Meuller 2010).

2. Scheme-2 (One-tier cooperative village breeding scheme) - Same as Scheme-1 but without a nucleus. The whole village sheep population is involved in selection. The villagers select breeding rams from across all the flocks in the village taken as one big breeding flock and use the selected rams communally (Gizaw et al. 2009; Haile et al., 2011; Mirkena et al., 2012). Animals screened from the village for high productivity based on the selection criteria could be transferred to a central test station for comparative ranking in a common environment (Wurzinger et al., 2008).

3. Scheme-3 (Dispersed village-based nuclei scheme) - Scheme-1 and -2 were designed to address genetic improvement within a village (i.e. within flock structure); they do not show how genetic improvement is implemented in the whole Menz sheep population in the five districts. Thus Scheme-3 (an extension of Scheme-2) was designed to scale up genetic improvement from single village-based activities to regional Menz sheep breeding programs. It involves establishing nuclei breeding villages where genetic improvement is generated, serving as sources of improved rams to the whole population of Menz sheep. The village nuclei will be located strategically across the Menz sheep breeding tract. It was calculated that nine village nuclei can serve the whole Menz sheep population. 
4. Scheme-4 (Two-tier central nucleus scheme) - This is the conventional central nucleus scheme (e.g. Bondoc and Smith, 1993; Gicheha et al., 2006) where genetic improvement is generated in a central nucleus flock located in a research/government farm which supplies improved rams to villages (e.g. Bondoc and Smith, 1993; Gicheha et al., 2006). The central nucleus could be operated by a private breeding company. During the first years of the program the central nucleus flock was planned to remain closed to gene inflow, but will be opened to accept elite ewes from village nuclei (see Schemes 5 and 6) as operational feasibility of such a scheme is ascertained.

5. Scheme-5 (Three-tier central nucleus scheme) - same as Scheme-4, but the central nucleus is linked to village-based multiplier nuclei. The village nuclei are operated by cooperative village breeding groups as described for Scheme-2.

6. Scheme-6 - is same as Scheme-5, but the village nuclei also practice selection of rams to be supplied to the village production unit. However, rams selected in the village nuclei are not used for breeding in the nuclei.

Selection of breeding stocks was based on BLUP breeding values in the central nucleus flock and on phenotypic values in village flocks. The sources of information for selection of breeding stocks in village flocks are the selection candidates' own SWT and their dams' lamb rearing record. Selection of female breeding stocks is to be practiced only in the central nucleus and village nuclei in Scheme-1. In the other village nuclei (Schemes 2, 3 and 6), selection of female breeding stocks was not found feasible. This is because selection of females in a cooperative way as described for cooperative ram selection in Scheme-2 above is not acceptable for farmers since, unlike communally used rams, females have to remain within the 
individual farmers' flocks. Secondly, selection of females within individual farmers' flocks is not effective because of the small individual flock sizes.

The inputs for biological, technical and economic parameters are shown in Table 1. The fixed costs include salaries of animal breeding experts for genetic evaluation, technical field assistant, and village coordinators, as well as costs for maintaining nucleus flocks, data processing facilities and supplies and communications. Costs for animal identification and recording traits are included as variable costs. The breeding program was planned for 10 years. The genetic parameters and economic values of traits used to design the breeding schemes are presented in Table 2.

Table 1. Biological, technical and economic parameters for six alternative breeding schemes for Menz sheep

\begin{tabular}{|c|c|c|c|c|c|c|}
\hline & \multicolumn{3}{|c|}{ Village-based breeding schemes } & \multicolumn{3}{|c|}{ Central nucleus breeding schemes } \\
\hline & Scheme-1 & Scheme-2 & Scheme-3 & Scheme-4 & Scheme-5 & Scheme- 6 \\
\hline \multicolumn{7}{|l|}{ Proportion of populations in: } \\
\hline Production unit & 0.90 & 1.0 & 0.90 & 0.90 & 0.95 & 0.95 \\
\hline Village nuclei & 0.10 & & 0.10 & & 0.045 & 0.045 \\
\hline Central nuclei & & & & 0.10 & 0.005 & 0.005 \\
\hline \multicolumn{7}{|l|}{ Number of villages in: } \\
\hline Production unit & 1 & 1 & 9 & 138 & 132 & 132 \\
\hline Village nuclei & 1 & & 1 & & 6 & 6 \\
\hline \multicolumn{7}{|l|}{ Lifetime use (years) of: } \\
\hline Rams in central nucleus & & & & 0.67 & 0.67 & 0.67 \\
\hline Rams in villages & 2.33 & 2.33 & 2.33 & 2.33 & 2.33 & 2.33 \\
\hline Ewes in central nucleus & & & & 4.0 & 4.0 & 4.0 \\
\hline Ewes in villages & 7.0 & 7.0 & 7.0 & 7.0 & 7.0 & 7.0 \\
\hline Number of lambings per year & 1.37 & 1.37 & 1.37 & 1.37 & 1.37 & 1.37 \\
\hline Mating ration $(\mathrm{F} / \mathrm{M})$ - villages & 30 & 30 & 30 & 30 & 30 & 30 \\
\hline Mating ration - central nucleus & & & & 45 & 45 & 45 \\
\hline Lambing interval (years) & 0.73 & 0.73 & 0.73 & 0.73 & 0.73 & 0.73 \\
\hline Conception rate & 0.90 & 0.90 & 0.90 & 0.90 & 0.90 & 0.90 \\
\hline
\end{tabular}




\begin{tabular}{lcccccc} 
Age at first lambing (years) & 1.5 & 1.5 & 1.5 & 1.5 & 1.5 & 1.5 \\
Twinning rate & 1.02 & 1.02 & 1.02 & 1.02 & 1.02 & 1.02 \\
Survival of Rams - villages & 0.85 & 0.85 & 0.85 & 0.85 & 0.85 & 0.85 \\
Survival of Rams - central nucleus & & & & 0.90 & 0.90 & 0.90 \\
Survival of ewes - villages & 0.85 & 0.85 & 0.85 & 0.85 & 0.85 & 0.85 \\
Survival of ewes - central nucleus & & & & 0.90 & 0.90 & 0.90 \\
Lamb weaning rate - village & 0.85 & 0.85 & 0.85 & 0.85 & 0.85 & 0.85 \\
Weaning rate - central nucleus & & & & 0.90 & 0.90 & 0.90 \\
Suitability for breeding & 0.90 & 0.90 & 0.90 & 0.90 & 0.90 & 0.90 \\
Fixed costs per ewe (Birr) & 72.0 & 4.80 & 4.80 & 16.14 & 64.50 & 64.50 \\
Variable costs per ewe (Birr) & 9.92 & 5.29 & 5.36 & 7.30 & 12.90 & 12.90 \\
\hline
\end{tabular}

Table 2. Phenotypic standard deviations $\left(\sigma_{p}\right)$, economic weights, heritabilities along diagonal, genetic (above diagonal), and phenotypic (below diagonal) correlations used in simulated selection in Menz sheep

\begin{tabular}{lllllll}
\hline Traits & $\begin{array}{l}\text { Economic } \\
\text { values (Birr) }\end{array}$ & $\sigma_{\mathrm{p}}$ & SWT & MWT & LTS & PWS \\
\hline SWT & 45.45 & 1.20 & 0.35 & 0.93 & 0.09 & 0.10 \\
MWT & 0.56 & 2.31 & 0.42 & 0.30 & 0.08 & 0.09 \\
LTS & 38.72 & 0.25 & 0.09 & 0.08 & 0.10 & -0.02 \\
PWS & 57.09 & 0.18 & 0.10 & 0.09 & 0.00 & 0.09 \\
\hline
\end{tabular}

$\sigma_{\mathrm{p}}$ Phenotypic standard deviation. SWT: six month weight, MWT: mature weight, LTS: litter size, PWS: preweaning survival. Source: Abegaz et al. (2002); Gizaw et al. (2004ab); Safari et al. (2005).

\section{RESULTS}

\section{Biological efficiencies}

The annual monetary genetic gains for the breeding objective were calculated as a sum of the products of the respective genetic gains and economic weights of the component traits (SWT, MWT, LTS, and PWS). Monetary genetic gains were higher for the central nucleus-based schemes (Schemes 4-6) than for the village-based schemes (Schemes 1-3; Table 3). Among the village-based schemes, the highest genetic gain was achieved from Scheme-1 in which both the 
male and female breeding stocks were selected. However, the genetic gains for all the central nucleus-based schemes were similar. The genetic gains in the selection criteria (SWT and PWS) and correlated responses in MWT and TWR are presented in Table 3.

Table 3. Genetic gain per year in the breeding objective and its component traits achieved from selection using six alternative Menz sheep breeding schemes

\begin{tabular}{lcccccc}
\hline & \multicolumn{3}{c}{ Village-based breeding schemes } & \multicolumn{2}{l}{ Central nucleus breeding schemes } \\
& Scheme-1 & Scheme-2 & Scheme-3 & Scheme-4 & Scheme-5 & Scheme-6 \\
\hline Breeding objective ${ }^{\prime}$ & 8.42 & 5.66 & 5.64 & 13.48 & 13.44 & 13.44 \\
SWT (kg) & 0.179 & 0.120 & 0.119 & 0.286 & 0.285 & 0.285 \\
MWT (kg) & 0.247 & 0.166 & 0.165 & 0.395 & 0.394 & 0.394 \\
LTS & 0.0019 & 0.0013 & 0.0013 & 0.0031 & 0.0031 & 0.0031 \\
PWS & 0.0015 & 0.0010 & 0.0010 & 0.0022 & 0.0022 & 0.0022
\end{tabular}

† The annual monetary genetic gains for the breeding objective were calculated as a sum of the products of the respective genetic gains and economic weights of the component traits (SWT: 6-month weight, MWT: mature weight, LTS: litter size and PWS: pre-weaning survival).

\section{Economic efficiencies}

The highest return to investment in the breeding program was obtained from Scheme-4 and the lowest from Scheme-5 (Table 4). Scheme-2 gave the highest returns among the villagebased schemes. Among the central nucleus-based schemes, direct provision of improved rams from the central nucleus to the production unit (Scheme-4) gave higher returns than the schemes involving intermediate multiplier village nuclei (Scheme-5 and 6). Introducing selection in the multiplier village nuclei (Scheme-6) increased the returns by $32.5 \%$ over Scheme-5. 
The annual costs were calculated per ewe in the whole population. These costs were higher for schemes that were designed for individual villages (Scheme-1 and 2) than schemes which addressed the whole population (Schemes 3-6). The relative profitability of the all schemes followed a similar pattern as for their returns, except that Scheme-2 was found to be less profitable than Scheme-6 despite its higher returns. Among the village-based schemes, Scheme-1 was found to be the most profitable design, but its superiority over the others was negligible. Scheme-4 was $72.7-126.2 \%$ more profitable than the other central nucleus-based schemes, and $91.3-99.0 \%$ more profitable than the village-based schemes.

Table 4. Returns, costs and profits per ewe per year (in Ethiopian Birr) obtained from selection in Menz sheep using six alternative breeding schemes

\begin{tabular}{ccccccc}
\hline & \multicolumn{3}{c}{ Village-based breeding schemes } & \multicolumn{2}{c}{ Central nucleus breeding schemes } \\
\hline & Scheme-1 & Scheme-2 & Scheme-3 & Scheme-4 & Scheme-5 & Scheme-6 \\
\hline Return/ewe/year & 44.24 & 46.94 & 36.76 & 73.42 & 31.81 & 42.15 \\
Cost/ewe/year & 7.70 & 9.87 & 0.97 & 2.23 & 0.35 & 0.93 \\
Fixed costs & 6.73 & 4.50 & 0.50 & 1.51 & 0.30 & 0.30 \\
Variable costs & 0.98 & 5.21 & 0.47 & 0.72 & 0.03 & 0.63 \\
Profit/ewe/year & 36.53 & 37.22 & 35.78 & 71.19 & 31.47 & 41.22
\end{tabular}

\section{Relative contributions to returns}

For all breeding schemes a greater percentage of the total returns were contributed by the breeding units (Table 5). The highest percentage contribution to returns was by the 
selection pathway where village nuclei rams were selected to breed village nuclei rams and ewes (Scheme-3). The percentage contributions of the production tier (village flocks) to the total returns were higher in the village-based breeding schemes than the central nucleus-based schemes. For the schemes where selection on the female side was practiced (Schemes 1, 4, 5 and 6) much of the returns resulted from selection of breeding rams rather than ewes.

Among the component traits of the breeding objective, genetic improvement in six month weight was virtually the sole contributor to returns on investment in all the six schemes. It accounted for $96.54 \%$ to $97.46 \%$ of the total returns. Mature weight, pre-weaning lamb survival, and twining rate accounted for $1.64-1.65 \%, 0.45-0.93 \%$, and $0.45-0.93 \%$ of the total returns, respectively.

Table 5. Percentage contributions of selection groups [i.e. selection of rams/ewes to breed rams/ewes either in the breeding tier ( $C N$ and $V N)$, multiplier tier (VN) or production tier (VF)] to annual returns per ewe in a simulated Menz sheep selection

\begin{tabular}{lcccccc}
\hline & \multicolumn{3}{c}{$V^{2}$} & \multicolumn{2}{c}{ Centrage-based schemes } & \multicolumn{2}{c}{ nucleus-based schemes } \\
\hline Selection groups $^{\dagger}$ & Scheme-1 & Scheme-2 & Scheme-3 & Scheme-4 & Scheme-5 & Scheme-6 \\
\hline CN rams to breed CN & - & - & - & 57.52 & 51.11 & 41.36 \\
CN ewes to breed CN & - & - & - & 20.29 & 16.62 & 13.57 \\
CN rams to breed VF & - & - & - & 22.19 & - & - \\
CN rams to breed VN & - & - & - & - & 32.27 & 15.41 \\
VN rams to breed VN & 52.13 & - & 65.21 & - & - & - \\
VN ewes to breed VN & 19.26 & - & 0.00 & - & - & 0.00 \\
VN rams to breed VF & 28.61 & - & 34.79 & - & 0.00 & 29.66 \\
VF rams to breed VF & - & 100 & - & - & - & - \\
\hline
\end{tabular}

${ }^{\dagger} \mathrm{CN}$ : central nucleus, breeding tier; VN: village nuclei, functioning as breeding and/or multiplier tier; VF: village flocks/production tier, receiving rams from the village, $\mathrm{CN}$ or VN. 


\section{Discussion}

We evaluated three village-based and three central nucleus-based sheep breeding schemes in terms of their bio-economic efficiency and operational feasibility under smallholder sheep farming systems in Menz region of Ethiopia. The results show that, among the villagebased schemes, generating genetic improvement in a village-based nucleus organized by a cooperating group of farmers within a village (Scheme-1) results in faster genetic progress than the other schemes evaluated in this study. However, a single-tier cooperative village breeding scheme (scheme-2) is economically more efficient. Besides, single-tier scheme seems to be operationally more feasible than two-tier scheme since running a nucleus within every cooperative village is rather unsustainable. Likewise, other cooperative schemes suggested for village breeding such as cooperative ram circles (Croston and Pollot, 1994; Kosgey, 2004) and sire referencing schemes (Lewis and Simm, 2000) are quite infeasible to implement among village flocks under low input smallholder farming systems, particularly in Menz region of Ethiopia. Ram circles could be suitable to extensive systems where individual flocks are large and herded separately (e.g. pastoral and Abergelle area in Ethiopia).

The genetic progress in SMW achieved in Scheme-2 is substantial. Estimates on response in SMW from simulated selection in Menz sheep are not available in the literature; but responses of $0.39-0.94 \mathrm{~kg}$ in yearling weight in simulated village-based selection in the local Menz, Afar, Bonga and Horro sheep have been reported (Mirkena et al., 2012). Selection for six month weight also resulted in a substantial improvement in ewe mature weight, which is expected to improve ewe mothering ability. However, excessive improvement in ewe weight could be considered a disadvantage. This is because the maintenance cost of an adult female 
sheep is proportionately related to her mature size and $50 \%$ of the total feed energy intake is used solely for body maintenance (Nitter et al., 1994). On the other hand, our results indicate that genetic improvement in reproductive traits through selective breeding is minimal. Genetic progresses in lamb survival and litter size were low both in the current and a previous simulation study on the local Horro, Bonga and Afar sheep breeds (Mirkena et al., 2012). The slow genetic progress in these traits is attributed to their low heritability and genetic correlations with growth traits (Safari et al., 2005) in the breeding objective.

The shortcoming of the one-tier cooperative scheme (Scheme-2) is that it is organized within individual villages. This entails that cooperative breeding groups need to be set up in each village in order to scale up the breeding program to the whole Menz sheep population. This is technically and logistically very challenging. An extension of Scheme-2 would be to develop the cooperative breeding villages into village breeding nuclei to provide improved rams for the nuclei and to the rest of the villages in the Menz sheep breeding tract (Scheme-3 in the current study). The nuclei would be set up strategically across the Menz sheep breeding tract to facilitate dissemination of improved rams. A similar scheme has been suggested by Mueller (2010) for low input systems.

Among the central nucleus schemes, the conventional scheme (Scheme-4) where genetic gain generated in the nucleus is directly disseminated to village flocks seems genetically and economically the most efficient. The genetic progress achieved in SMW $(0.29 \mathrm{~kg})$ is comparable with the response achieved from actual selection $(0.34 \mathrm{~kg})$ in a nucleus flock of Menz sheep (Gizaw et al., 2007). Yet, its operational feasibility is questionable. Evaluation of breeding schemes for smallholder sheep farming systems needs to include appraisal of their 
feasibility to implement besides their bio-economic efficiencies. Scheme-4 requires establishing and running a very large central nucleus flock of about 11241 ewes to provide improved rams to the whole Menz sheep population. Establishing, maintaining and running such a large nucleus flock may not be sustainable in Ethiopia and most likely in other developing countries as well in view of the long term financial support and commitment required. Indeed, such government-run central nucleus breeding programs have failed in East Africa and India because of lack of efficient management (Okeyo, 2002; Ahuya et al., 2005; Kosgey, 2004; Singh et al., 2005), though there are some successful cases (e.g., Dempfle and Jaitner, 2000; Yapi-Gnoar'et al., 2000; Von Wielligh, 2001). Involvement of private breeding companies in nucleus breeding programs does not seem feasible in Ethiopia in the near future. However, there is an option to revise government-run nucleus schemes to improve its operational feasibility as discussed below.

The central nucleus scheme in this study was designed with a closed nucleus where gene flow is restricted to provision of rams from the nucleus to villages. Open nucleus schemes have been shown to yield faster genetic progress and higher profit per ewe (Kinghorn, 2000), lower rate of inbreeding (Kosgey, 2004), and encourage more farmer participation (Bondoc \& Smith 1993). However, open systems could make the central nucleus scheme even more infeasible under low input smallholder systems where infrastructure and logistics required to select and transfer elite ewes from villages to the nucleus are limited. Gicheha et al. (2006) also justifies the difficulty of establishing open nucleus schemes in developing countries such as Kenya. The expected higher inbreeding rates in closed than in open systems can be overcome by adopting 
mate selection procedures (Meuwissen, 1997) which maximize the response of selection with a predefined rate of inbreeding.

Comparison of central nucleus- and village-based schemes showed that higher genetic gains could be achieved from selection programs that are organized with a central nucleus flock than from village-based breeding schemes without a central nucleus. This is to be expected as selection was on BLUP breeding values and both male and female selection pathways were modeled in the central nucleus scheme. Kosgey (2004) also found that running a closed nucleus scheme with selection on BLUP breeding values had a $6-24 \%$ advantage over a cooperative village 'ram circle' scheme where selection was on candidates' phenotypes. In general, the conventional pyramidal nucleus breeding structure is adopted by the majority of the populations of international sheep breeds and it can be very effective when the size and operation of the nucleus layer is adequate and dissemination is operational (Mueller, 2010). In accordance to their genetic efficiencies, the central nucleus based schemes (particularly Scheme 4 and 6) were found to be superior in economic terms as well. Economic efficiency of breeding schemes is determined by the relative selection costs incurred, besides to genetic gains achieved. The results indicate that breeding programs designed for individual villages (Scheme 1 and 2 ) would entail higher costs per ewe than those that serve the whole population of a breed (Scheme 3-6). Yet, evaluation of economic efficiencies of breeding schemes needs to consider the relative distribution of economic returns to the various producer/breeder groups across the population breeding structure (central nucleus breeders, village nucleus breeders/multipliers, village producers). For instance, a one-tier village-based breeding scheme (Scheme-2 in this study), where $100 \%$ of the return is retained by the producer farmers, could 
be the best alternative if the target of the breeding program is to benefit the smallholder producers.

The choice of breeding schemes does not have to be restricted exclusively to central nucleus versus village-based schemes; a combination of the two as well need to be considered to maximize genetic progress/profitability and facilitate operation of breeding programs. A modified version of the conventional central nucleus scheme designed in the current study (Scheme-4) links a central nucleus with village-based nuclei which serve as both multipliers and generators of genetic improvement. This scheme avoids the need to establish unaffordable large central nucleus required by the conventional central nucleus scheme, gives substantial genetic gain and profit, and allows greater participation of sheep keepers in the design and implementation of the breeding program. Introduction of biotechnology tools, particularly artificial insemination, in the breeding program could facilitate operation of breeding programs by overcoming the need for large nucleus flocks and logistical limitations to transfer genetic gains across the breeding structure.

\section{Conclusion}

This study evaluated two sets of sheep breeding schemes (village-based and central nucleus-based) for setting up sheep breeding programs under smallholder farming systems. The choice of village- or central nucleus-based breeding programs would depend on local conditions with respect to availability of infrastructures and logistics. Linking central nucleus flocks with village-based nuclei (Scheme-6) is found to be a feasible option and could overcome the operational difficulties of the conventional central nucleus breeding scheme. Among the villagebased schemes, cooperative village breeding scheme (Scheme-2) to design village level 
programs or its extension (Scheme-3) to design breeding programs addressing the whole sheep population of a breed was found to be the most feasible schemes. To control inbreeding, villagers in a cooperative village need to be organized into ram groups of 3-4 farmers to use a ram communally and selected rams need to be allocated to groups other than their origin. The breeding schemes evaluated in this study were modeled with baseline levels of the biological, economic and population parameters. Thus the most efficient and operationally feasible schemes (scheme 2 and 6 ) need to be optimized with alternative levels of the parameters such as different central nucleus sizes and village nuclei sizes.

\section{Acknowledgements}

This paper is produced as part of the post-doctoral research by the first author. The research is sponsored by the German Development Cooperation (DAAD) and the International Livestock research Institute (ILRI). We greatly acknowledge the assistance of .... with ZPLAN.

\section{References}

Abegaz S., G. Duguma, E. Negussie, U. Gelmesa, F. Terefe and J.E.O. Rege, 2002. Factors affecting reproductive performance and estimates of genetic parameters of litter size in Horro sheep. J. Agri. Sci., 139: 79-85.

Ahuya, C.O., Okeyo, A.M.,Mwangi-Njuru, Peacock, C., 2005. Development challenges and opportunities in the goat industry: The Kenya experience. Small Rumin. Res. 60, 197-206. 
Bondoc O.L., Smith C. 1993. Deterministic genetic analysis of open nucleus breeding schemes for dairy cattle in developing countries. J. Anim. Breed. Genet., 110, 194-208.

Bosman H.G., Moll H.A.J., Udo H.M.J. (1997). Measuring and interpreting the benefits of goat keeping tropical farm systems. Agricultural Systems 53:349-372.

Croston, D., Pollot, G., 1994. Planned sheep production. Blackwell Scientific Publications, London.

Duguma, D., T. Mirkena, A. Haile, A. M. Okeyo, M. Tibbo, B. Rischkowsky, J. Solkner, M. Wurzinger. 2011. Identification of smallholder farmers and pastoralists' preferences for sheep breeding traits: choice model approach. Animal 5:1984-1992.

Nitter, G., H.U. Graser and S. A. Barwick. 1994. Evaluation of Advanced Industry Breeding Schemes for Australian Beef Cattle. I. Method of Evaluation and Analysis for an Example Population Structure. Aust. J. Agric. Res., 1994, 45, 1641-56.

Gizaw S, Komen H and van Arendonk JAM 2009. Optimal village breeding schemes under smallholder sheep farming systems. Livestock Science 124, 82-88.

Gizaw S, Lemma S, Komen $\mathrm{H}$ and van Arendonk JAM 2007. Estimates of genetic trends and genetic parameters for live weight and fleece traits in Menz sheep. Small Ruminant Research 70, 145-153.

Gizaw S. and B.K. Joshi. 2004a. Genetic and non-genetic factors affecting survivability of Menz and Awassi x Menz crossbred sheep in Ethiopia. Indian Journal of Animal Sciences, 74(8):887-889. 
Gizaw S. and B.K. Joshi. 2004b. Estimates of genetic parameters for growth traits in Menz and Awassi x Menz crossbred sheep in Ethiopia. Indian Journal of Animal Sciences 74(8):864867.

Haile A, Wurzinger, M, Mueller J, Mirkena T, Duguma G, Mwai O, Sölkner J and Rischkowsky B 2011. Guidelines for setting up community-based sheep breeding programs in Ethiopia. ICARDA tools and guidelines No.1, ICARDA, Aleppo, Syria.

Kinghorn B. (2000) Nucleus breeding schemes. In: B. Kinghorn, J. van der Werf, M. Ryan (eds), Animal Breeding, Use of New Technologies. Post Graduate Foundation in Veterinary Science of the University of Sydney, Sydney, Australia, pp. 152-158.

Kosgey, I.S., Okeyo, A.M., 2007. Genetic improvement of small ruminants in low input, smallholder production systems: technical and infrastructural issues. Small Rumin. Res. 70, 76-88.

Kosgey, I.S., R.L. Baker, H.M.J. Udod, J.A.M. Van Arendon. 2006. Successes and failures of small ruminant breeding programmes in the tropics: a review. Small Rumin. Res. 61:13-28.

Kosgey, I.S., Okeyo, A.M. 2004. Breeding objectives and breeding strategies for small ruminants in the tropics. PhD thesis, Wageningen University, Wageningen.

Lewis, R.M., Simm, G. 2000. Selection strategies in sire referencing schemes in sheep. Livest. Prod. Sci. 67:129-141.

Gicheha, M.G., I.S. Kosgey, B.O. Bebe \& A.K. Kahi. 2006. Evaluation of the efficiency of alternative two-tier nucleus breeding systems designed to improve meat sheep in Kenya. J. Anim. Breed. Genet. 123: 247-257. 
Meuwissen, T.H.E. 1997. Maximizing the response of selection with a predefined rate of inbreeding. J Anim Sci, 75:934-940.

Mirkena, T., G. Duguma, A. Willam, M. Wurzinger, A. Haile, B. Rischkowsky. 2012. Communitybased alternative breeding plans for indigenous sheep breeds in four agro-ecological zones of Ethiopia. J. Anim. Breed. Genet. 129:244-253.

Mueller JP. 2010. Experiences with breeding structures for genetic improvement of small ruminants. Commercialization of Livestock Agriculture in Africa: Challenges and Opportunities' The $5^{\text {th }}$ All Africa Conference on Animal Agriculture and the $19^{\text {th }}$ Annual Meeting of the Ethiopian Society of Animal Production (ESAP), Book of Abstracts, October 25 - 28, 2010, Addis Ababa, Ethiopia.

Okeyo, A.M., 2002. Challenges in goat improvement in developing rural economies of Eastern Africa with special reference to Kenya. In: Ahuya, C.O., van Houton (Eds.), Proceedings of Goat Development in Eastern Africa Workshop. 8-I1 December 1997, Izaac Walton Inn, Embu, Kenya, pp. 55-66.

Safari, E., Fogarty, N.M., Gilmour, A.R., 2005. A review of genetic parameter estimates for wool, growth, meat and reproduction traits in sheep. Livest. Prod. Sci. 92, 271-89.

Singh, S.K., Singh, M.K., Rai, B., 2005. Evaluation of different goat production systems in India and breeding strategy for improvement. In: Proceeding of Eighth National Conference on Animal Genetics and Breeding; National Livestock Breeding Policy, 8-10 March 2005, Central Institute for Research on Goats, Makhdoom, Farah-281 122, Mathrua (UP) India, pp. 72-79. 
Smith C. 1988. Genetic improvement of livestock in developing countries using nucleus breeding units. World Anim. Review 65:2-10.

Sölkner, J., Nakimbugwe, H.,Valle Zarate, A., (1998). Analysis of determinants for success and failure of village breeding programs. Proceedings of the 6th World Congress on Genetics Applied to Livestock Production, 25:273-281.

von Wielligh, W., 2001. The Damara sheep as adapted sheep breed in Southern Africa. In: Community-Based Management of Animal Genetic Resources, Proceedings of theWorkshop, 7-11 May 2001, Mbabane, Swaziland, pp. 173-175.

Willam, A., Nitter, G., Bartenchlager, H., Karras, K., Niebel, E., Graser, H.-U. (2008). ZPLANmannual for a PC-program to optimize livestock selection schemes. Manual Version 2008 for Source Code "z10.for". Institute of Animal Production in the Tropics and Subtropics. Universität Hohenheim, Stuttgart, Germany.

Wurzinger, M., Willam, A., Delgado, J., Nurnberg, M., Zarate, A.V., Stemmer, A., Ugarte, G., Solkner, J., 2008.. Design of a village breeding program for a llama population in the High Andes of Bolivia. J. Anim. Breed. Genet. 125, 311-319 311.

Yapi-Gnoar'e, C.V., 2000. The open nucleus breeding programme of the Djallonk'e sheep in C^ote D’Iv^oire. In: Galal, S., Boyazoglu, J., Hammond, K. (Eds.), Workshop on Developing Breeding Strategies for Lower Input Animal Production Environments, 22-25 September 1999, Bella, Italy, ICAR Technical Series 3, 283-292. 